\title{
Distal Radioulnar Joint Synovial Osteochondromatosis - A Case Report and Review of Literature
}

\begin{abstract}
Synovial chondromatosis is a rare benign clinical condition, with a rare location in the wrist. This study presents a case of synovial chond romatosis in the distal ra dioulnar jo int (DRUJ ) treated successfully with surgical excision. A 45-year old right handed male presented in our department, with a 3-year history of wrist pain, without any trauma. He referred a lump around the right DRUJ which fluctuated in size associated with frequent pain, weakness and a popping with occasional locking of the wrist. Clinical examination showed a painful lobulated swelling over right DRUJ with a crepitus at the lateral stress of the joint. X-rays and MRI showed multiple coarse calcific densities around the DRUJ. The patient was treated with surgical removal of calcified loose bodies originated by the DRUJ. Biopsy results were consistent with synovial chondromatosis. One year postoperatively, patient was pain-free, with a full range of motion and no signs of local recurrence.
\end{abstract}

Keywords: Synovial steochondromatosis; Distal radioulnar joint; Case report

\section{Introduction}

Synovial chondromatosis is a rare benign clinical condition, characterized by synovial connective tissue metaplasia and the formation of multiple loose cartilaginous nodules within the synovial membrane $[1,2]$. The condition commonly affects large joints, such as knee and shoulder, but rarely can be located in wrist and hand [3-5]. Although the precise pathophysiology of the disease is poorly understood, it has been suggested that multipotential synovioblasts undergo multifocal metaplasia to form chondroblasts, resulting in the formation of cartilaginous nodules [6]. Its low prevalence and nonspecific symptoms engender diagnostic difficulties and hence delay of treatment. Hereby, we report a rare case of synovial chondromatosis in the distal radioulnar joint (DRUJ) and a review of the literature.

\section{Case Report}

A 45-year old right handed injection moulders presented in our department, with a 3-year history of wrist pain, without any trauma. He referred a lump around the right DRUJ which fluctuated in size associated with frequent pain, weakness and a popping with occasional locking of the wrist. The patient complained about a general deterioration in wrist function and a worsening painful swelling over last 6 months, affecting his work and daily activities, as he is a keen cricketer.

Clinical examination showed a lobulated swelling over right DRUJ with normal skin. There was no pain in stressing DRUJ with a good range of motion (ROM) and no signs of ulnar abutment. However, stressing DRUJ stability from volar to dorsal was exquisitely tender, producing a click and also stressing the extensor carpi ulnaris (ECU) tendon was uncomfortable without any signs of subluxation. He has had an injection study previously. Anteroposterior and lateral wrist radiographs showed multiple coarse calcific densities in the right DRUJ (Figures 1A-1B). A magnetic resonance imaging (MRI) scan

\section{Journal of \\ Orthopedics \& Rheumatology}

\section{Thomas Laios ${ }^{1 *}$, Tarek Boutefnouchet ${ }^{1}$ Gunaratnam Shyamalan ${ }^{1}$, Medhat Zekry ${ }^{1}$ and Panagiotis Lepetsos ${ }^{2}$}

${ }^{1}$ Department of Trauma \& Orthopaedics, NHS Foundation Trust, UK

${ }^{2} 4^{\text {th }}$ Department of Trauma \& Orthopaedics, KAT Hospital, Greece *Address for Correspondence

Thomas Laios, Department of Trauma \& Orthopaedics, Heart of England, NHS Foundation Trust, UK, Tel: +447872652727; Email: thomaslaios2@gmail.com

Submission: 13 February, 2018

Accepted: 21 May, 2018

Published: 28 May, 2018

Copyright: (c) 2018 Laios T, et al. This is an open access article distributed under the Creative Commons Attribution License, which permits unrestricted use, distribution, and reproduction in any medium, provided the original work is properly cited.

also depicted multiple coarse calcific densities around the distal ulna and the DRUJ (Figures 2A-2C). Triangular fibrocartilage complex (TFCC) appeared intact. Focal erosion was identified in the distal ulna laterally and at the level of the DRUJ. Erosions were also identified in the carpal bones.

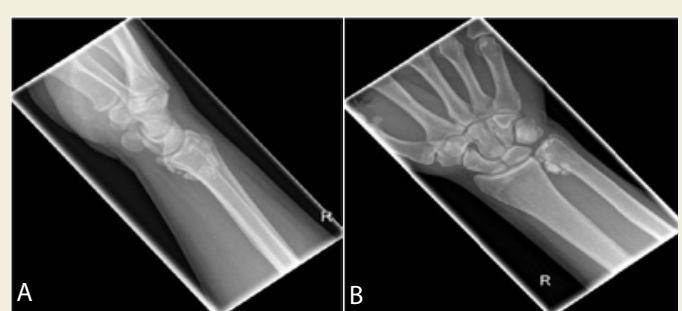

Figure 1: A: Initial anteroposterior wrist x-rays. B: Initial lateral wrist x-rays.

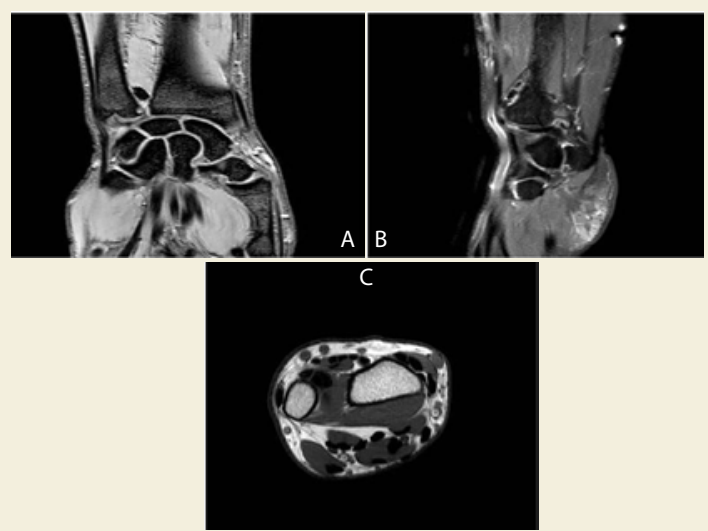

Figure 2: A: MRI scans of the right wrist, showing the lesion. B: MRI scans of the right wrist, showing the lesion. C: MRI scans of the right wrist, showing the lesion. 
Citation: Laios T, Boutefnouchet T, Shyamalan G, Zekry M, Lepetsos P. Distal Radioulnar Joint Synovial Osteochondromatosis - A Case Report and Review of Literature. J Orthopedics Rheumatol. 2018; 5(1): 3

Under these circumstances, a surgical management was decided. Through direct dorsal approach over DRUJ, extensor digiti minimi tendon was lifted. Thirteen smooth cartilaginous tissue samples were removed easily by milking DRUJ laterally. The sizes of the removed lesions varied from $2 \times 3 \mathrm{~mm}$ to $7 \times 11 \mathrm{~mm}$. Histopathological examination demonstrated nodular cartilaginous tissue with a distinct zonation, a thin rim of fibrous tissue at the periphery, early calcification, variable cellularity and non-viable cartilaginous sites, findings consistent with synovial chondromatosis. After tissue excision, DRUJ was intraoperatively stable and no additional stabilization was required. Postoperatively, the patient started active and passive ROM exercises. Within 4 weeks, the patient was pain-free, without residual motion deficit and full active ROM was regained. Postoperative radiographs were clear of any evidence of loose bodies or remaining calcified tissues. At 12 months final follow-up, no local recurrence was observed.

\section{Discussion}

Synovial chondromatosis is a proliferative disease with unknown etiology. It may be of cartilaginous or of osteocartilaginous origin, arising from joint synovium or tendon sheaths and resulting in an accumulation of intra-articular cartilaginous nodules. The disease affects mainly $3^{\text {rd }}$ and $4^{\text {th }}$ decade males with special predilection of shoulder, elbow, hip, knee and ankle. Cases affecting the hand and wrist are rare, with one retrospective case series reporting a prevalence of $7.5 \%$ among 53 synovial chondromatosis cases in comparison with $74 \%$ in the knee [6,7]. Synovial chondromatosis of the wrist and hand occurs most commonly from the ages of 30 to 60 years. Prior injury of the wrist does not appear to increase the likelihood of developing this condition in the DRUJ [6]. In our case, the patient was 45 years old without any previous history of hand trauma.

Milgram JW classified the disease process into 3 phases: the early phase-active intrasynovial chondrometaplasia without loose bodies; the transitional phase-active intrasynovial chondrometaplasia with loose bodies; and the late phase-loose bodies without intrasynovial chondrometaplasia [8]. Our case can be classified in the $2^{\text {nd }}$ stage, as loose bodies were portrayed in simple $\mathrm{x}$-rays and biopsy showed signs of active synovial disease. As mentioned in our case, common clinical features include mild pain, swelling, stiffness, locking and crepitus due to lose bodies [9]. Ballet FL et al. reported a case of synovial chondromatosis in which the DRUJ was locked and damaged by an impinging loose body [7]. Differential diagnosis includes tendonitis, chronic inflammatory arthritis, broken osteophytes, osteochondritis dissecans, synovial sarcoma and osteosarcoma. X-rays have low specificity, as they demonstrate scattered calcifications, especially in early stages. Ultrasound and MRI are helpful diagnostic imaging studies [3]. In our case, MRI showed focal erosions and demonstrated the integrity of nearby tissues, helping in the differential diagnosis of the disease. However, final diagnosis is defined by the results of the histopathologic examination. A $17 \%$ rate of recurrence has been reported in patients with synovial chondromatosis of the wrist [10]. Malignant transformation of synovial chondromatosis of the wrist has not been reported [10].

Though spontaneous regression has been reported, the disease is often progressive and can potentially destroy joints, due to the abrasive effect of loose bodies, and thus, their surgical removal, is required [11]. As synovial chondromatosis refers to the formation of cartilage from transformed synovial cells, the use of additional synovectomy in order to prevent local recurrence has been advocated by several authors. Synovectomy may be total or partial and can be carried out by shaving the line of the joint. Von Schroeder HP et al. reported a case of a 16-year old man with synovial osteochondromatosis of right DRUJ, treated with removal of 13 loose bodies and synovectomy [12]. Rogachefsky RA et al. presented a case of a 34-year-old man with synovial chondromatosis of the left DRUJ, treated with synovectomy and removal of cartilage-like fragments [13]. Inada $Y$ et al. described a case of synovial chondromatosis of DRUJ in which there was extensive involvement of the TFCC. The patient was treated with synovectomy, excision of osteochondral bodies and removal of the entire TFCC [14]. Lyritis $\mathrm{G}$ noted a case of synovial chondromatosis involving multiple small free bodies inside DRUJ. The patient was treated with removal of 8 cartilagenous nodules, without synovectomy [15]. In two cases of DRUJ synovial chondromatosis described by Ono $\mathrm{H}$ et al., patients were treated with excision of synovium and removal of all chondral bodies [9]. Recently, a case of recurrence of synovial chondromatosis of DRUJ was reported, 9 years after initial removal of calcified deposits. The patient was re-operated with additional synovectomy. Authors attributed recurrence to the inadequate resection at the initial surgery [10]. A retrospective study of 13 patients with synovial chondromatosis of the knee treated with total synovectomy showed lower rate of recurrence [16]. In our case, we chose not to perform a total synovectomy, as we believe that extensive removal of abnormal tissues was sufficient to prevent local recurrence.

\section{Conclusion}

Although quite rare in the hand and the wrist, synovial chondromatosis must be taken into consideration in the differential diagnosis in a patient presenting with atraumatic chronic pain, swelling and crepitus of the DRUJ. Surgical exploration of the joint, removal of loose bodies alone or combined with synovectomy, is the recommended treatment.

\section{References}

1. Levine BD, Motamedi K, Seeger LL (2016) Synovial tumors and proliferative diseases. Rheum Dis Clin North Am 42: 753-768.

2. Sim FH, Dahlin DC, Ivins JC (1977) Extra-articular synovial chondromatosis. J Bone Joint Surg Am 59: 492-495.

3. Leekam RN, Voorneveld CR (1996) Synovial osteochondromatosis of the distal radioulnar joint: ultrasound diagnosis. J Clin Ultrasound 24: 207-208.

4. De Smet L, Van Wetter P (1987) Synovial chondromatosis of the distal radioulnar joint. Acta Orthop Belg 53: 106-108.

5. Slesarenko YA, Hurst LC, Dagum AB (2004) Synovial chondromatosis of the distal radioulnar joint. Hand Surg 9: 241-243.

6. Wong SH, Salama S, Thoma A (2003) Synovial chondromatosis of the hand: Three case reports and literature review. Can J Plast Surg 11: 47-52.

7. Ballet FL, Watson HK, Ryu J (1984) Synovial chondromatosis of the distal radioulnar joint. J Hand Surg Am 9: 590-592.

8. Milgram JW (1977) Synovial osteochondromatosis: a histopathological study of thirty cases. J Bone Joint Surg Am 59: 792-801.

9. Ono $\mathrm{H}$, Yajima $\mathrm{H}$, Fukui A, Tamai $\mathrm{S}$ (1994) Locking wrist with synovia chondromatosis: report of two cases. J Hand Surg Am 19: 797-799.

10. Reverte Vinaixa MM, Singh R, Monyart JM, Llado GD, Dominguez MP, et al. (2012) Wrist synovial chondromatosis: case report and literature review. Hand Surg 17: 233-238 
Citation: Laios T, Boutefnouchet T, Shyamalan G, Zekry M, Lepetsos P. Distal Radioulnar Joint Synovial Osteochondromatosis - A Case Report and Review of Literature. J Orthopedics Rheumatol. 2018; 5(1): 3

\section{ISSN: $2334-2846$}

11. Loonen MP, Schuurman AH (2005) Recurrent synovial chondromatosis of the wrist: case report and literature review. Acta Orthop Belg 71: 230-235.

12. von Schroeder HP, Axelrod TS (1996) Synovial osteochondromatosis of the distal radio-ulnar joint. J Hand Surg Br 21: 30-32.

13. Rogachefsky RA, Zlatkin MB, Greene TL (1997) Synovial chondromatosis of the distal radioulnar joint: a case report. J Hand Surg Am 22: 1093-1097.

14. Inada Y, Fukui A, Maeda M, Tamai S, Inada M (1990) Reconstruction of the triangular fibrocartilage complex after surgery for treatment of synovial osteochondromatosis of the distal radioulnar joint. J Hand Surg Am 15: 921-924.

15. Lyritis G (1976) Synovial chondromatosis of the inferior radio-ulnar joint. Acta Orthop Scand 47: 373-374.

16. Ogilvie-Harris DJ, Saleh K (1994) Generalized synovial chondromatosis of the knee: a comparison of removal of the loose bodies alone with arthroscopic synovectomy. Arthroscopy 10: 166-170. 